\title{
Short Time Ion Nitriding of AISI 420 Martensitic Stainless Steel to Improve Wear and Corrosion Resistance
}

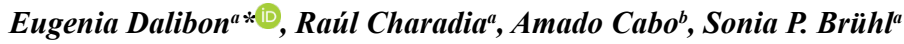 \\ ${ }^{a}$ Universidad Tecnológica Nacional (UTN-FRCU), Grupo de Ingeniería de Superficies, Ing. Pereira \\ 676, E3264BTD, Concepción del Uruguay, Argentina \\ ${ }^{b}$ IONAR S.A., Arias 3422, C1430CRB, Buenos Aires, Argentina
}

Received: July 05, 2019; Revised: November 29, 2019; Accepted: December 19, 2019

\begin{abstract}
Plasma nitriding has become a powerful tool to improve wear resistance of stainless steels and sustain or improve corrosion resistance with an adequate selection of process parameters. In this work, the short treatment route with temperatures above $400^{\circ} \mathrm{C}$ was selected for AISI 420 stainless steel. After the nitriding process, a wide nitrided layer, with good wear and corrosion properties was simultaneously obtained with selected parameters. A 5 hours treatment at $420{ }^{\circ} \mathrm{C}$ resulted in a 10 $\mu \mathrm{m}$ nitrided layer. XRD revealed an expanded Fe- $\alpha$ layer with Fe nitrides but no signal of $\mathrm{CrN}$ was found. Wear resistance was improved three and four times in erosion and sliding tests compared to the non-nitrided material. Corrosion resistance was tested in anodic polarization experiments in a $\mathrm{NaCl}$ solution. In this test, the samples treated in the short time process presented the best results.
\end{abstract}

Keywords: Plasma nitriding, martensitic stainless steel, erosion, corrosion.

\section{Introduction}

Martensitic stainless steels are widely used for the manufacturing of components that require good mechanical properties and moderate corrosion resistance. For these applications, plasma nitriding can be used to increase surface hardness and wear resistance and consequently improve their performance and lifespan ${ }^{1-4}$. Several studies about the wear behaviour of nitrided martensitic stainless steel have been carried out and many authors have reported that the plasma nitriding process allows the improvement of tribological properties ${ }^{2,5-7}$. In this kind of steels, a nitrided layer with both a high nitrogen content zone and a diffusion zone is formed ${ }^{5,7}$. The nitrided layer retains its martensitic structure with a lattice parameter larger than the bulk. This phase is called "expanded martensite" and sometimes, also $\gamma$ '- $\mathrm{Fe}_{4} \mathrm{~N}$ and $\varepsilon-\mathrm{Fe}_{2-3} \mathrm{~N}$ nitrides precipitate in the nitrided layer ${ }^{8-11}$. This nitrided layer increases the surface hardness and improves the tribological properties as mentioned above; however, the corrosion resistance can be affected depending on the process parameters. This is due to the chromium nitrides precipitation which reduces the free chromium in solid solution and as a consequence, the ability of the material to build the passive film for corrosion protection ${ }^{1,2,12}$.

There are publications about nitrided martensitic stainless steel corrosion behaviour at different temperature and long treatments (15 and 20 hours). It was reported that it is possible to obtain a good corrosion resistance (in the AISI 420 and AISI 410 stainless steels) when the expanded martensite without chromium nitrides precipitation is formed at low temperature ${ }^{2,13}$.
On the other hand, some authors found a good corrosion resistance in plasma nitrided AISI 410 martensitic stainless steel for 20 hours at high temperatures, $460^{\circ} \mathrm{C}$ and $500^{\circ} \mathrm{C}$. In this case, the authors claimed that the dense iron nitride layer exerted more influence over the corrosion protection than the passive oxide layer ${ }^{12}$. Regarding the short nitriding treatments, Scheuer et.al performed nitriding treatments at different temperatures for 4 and 8 hours. They made a detailed study of microstructure and detected chromium nitrides precipitation when the process was carried out at $450{ }^{\circ} \mathrm{C}$ for 4 hours ${ }^{14-16}$; however, they did not evaluate the corrosion behaviour. Li et al. analyzed the wear and corrosion behaviour of AISI 420 martensitic stainless steels that were nitrided at different temperatures for 6 hours using the anodic potential active screen plasma nitriding technique. They found that the nitrided samples at $480{ }^{\circ} \mathrm{C}$ showed the best wear and corrosion resistance. Under these conditions, it was verified that the nitrided layer was composed of nitrogen expanded martensite and iron nitrides ${ }^{1}$. It could be stated that there is no agreement regarding the nitriding process conditions to obtain a nitrided layer with a good corrosion behaviour, therefore, it might be necessary to propose a new combination of parameters.

In this work, the route of short time-high temperature process was selected, and it was then compared with the traditional long time-low temperature process. The aim was to find a set of plasma process parameters to nitride AISI 420 stainless steel and at the same time obtain a good wear and corrosion resistance nitrided layer. The technological importance of using short time treatments was considered since they allow an increase in efficiency and energy saving. 


\section{Experimental}

Discs-shaped samples, $2 \mathrm{~mm}$ high and $25 \mathrm{~mm}$ in diameter, were cut from an AISI 420 martensitic stainless steel plate, with a chemical composition of $0.38 \mathrm{wt} \% \mathrm{C}, 13 \mathrm{wt} \% \mathrm{Cr}, 0.44$ wt $\%$ Mn, 0.42 wt $\%$ Si, 0.07 wt $\%$ Mo, 0.02 wt $\% \mathrm{P}$ and $\mathrm{Fe}$ as balance. They were submitted to a standard thermal treatment recommended for this steel in order to obtain a martensitic structure. First, they were subjected to preheating at $800{ }^{\circ} \mathrm{C}$ for 15 minutes. Secondly, they were heated at $1030^{\circ} \mathrm{C}$ for 30 minutes. Then, they were quenched in agitated air, and finally tempered at $260^{\circ} \mathrm{C}$ for 2 hours. They were prepared with $\mathrm{SiC}$ grit paper from \#120 to \#1000 and later polished with $1 \mu \mathrm{m}$ diamond powder. The surface roughness Ra was $(0.0310 \pm 0.0006) \mu \mathrm{m}$

Plasma nitriding treatments were performed in an industrial equipment at IONAR S.A. (Buenos Aires, Argentina) using a DC pulsed plasma discharge and in a $20 \% \mathrm{~N}_{2}-80 \% \mathrm{H}_{2}$ atmosphere. The nitriding processes were carried out at different temperatures and durations as it is shown in Table 1.

Table 1. Plasma nitriding parameters

\begin{tabular}{cc}
\hline Conditions & Parameters \\
\hline $\mathrm{N} 1$ & $390{ }^{\circ} \mathrm{C}, 10 \mathrm{~h}$ \\
$\mathrm{~N} 2$ & $390^{\circ} \mathrm{C}, 5 \mathrm{~h}$ \\
$\mathrm{~N} 3$ & $420^{\circ} \mathrm{C}, 5 \mathrm{~h}$ \\
$\mathrm{~N} 4$ & $420^{\circ} \mathrm{C}, 4 \mathrm{~h}$ \\
\hline
\end{tabular}

It could be stated that the first condition N1 (low temperature and medium/long duration) is the one corresponding to control, because it belongs to the group of parameters which is convenient for both wear and corrosion resistance in the cited literature $2,13,14$.

The surface hardness and the hardness depth profile of the nitrided samples were measured using a Vickers Indenter with a $25 \mathrm{~g}$ load. The microstructure was analyzed by XRD, OM and SEM (FEI Quanta 250 model). All SEM images were obtained in SE mode. The XRD measurements were carried out in a PANalytical diffractometer with Bragg Brentano geometry using $\mathrm{CuK}_{\alpha}$ radiation. The chemical composition of the nitrided layer was measured in depth by GDOES (Glow-Discharge Optical Emission Spectroscopy). The GDOES equipment was previously calibrated for the nitrogen detection in nitrided samples. The measurements were performed using a type RF1000 Horiba Jobin Yvon equipment. The gradual ablation of surface layers was achieved by using Argon ions bombardment from radiofrequency plasma with $30 \mathrm{~W}$ power.

The tribological behaviour was evaluated using pin on disks tests following the ASTM G99-95 standard, using $5 \mathrm{~N}$ load and an alumina ball $6 \mathrm{~mm}$ in diameter acting as counterpart. The track radius was $7 \mathrm{~mm}$, the tangential velocity was $10 \mathrm{~cm} / \mathrm{s}$ and the wear length, $500 \mathrm{~m}$.
The volume loss was calculated from the cross sectional profile of the wear scar and measured by a mechanical profilometer. The friction coefficient was also measured in the same tests, calculating the average value among one thousand seconds of the tests, once the steady state was reached. The erosion resistance was evaluated in a tailor-made machine in a water and sand mixture for eight hours. The impact angle was $30^{\circ}$ and the flux was $5.8 \mathrm{~mm}^{3} / \mathrm{h}$. The sand granulometry was AFS 50. The samples were weighed before and after the tests. The tested surfaces were examined by SEM.

In order to evaluate the corrosion behaviour, polarization tests were carried out in an electrochemical cell with a testing area of $0.28 \mathrm{~cm}^{2}$ over the sample, and sealed with an o-ring. Three experiments were performed on each sample and only one curve is shown, which represents the corrosion behavior of the above experiments. A deaireated 3.5\% $\mathrm{NaCl}$ solution $(\mathrm{pH}$ 6.5) at room temperature was used as electrolyte; the reference electrode was a standard Calomel, the counter electrode was a Pt wire and the working electrode was the sample. The sweeping rate was $1 \mathrm{mV} / \mathrm{s}$. The surface was observed by SEM after the corrosion tests.

\section{Results and Discussion}

\subsection{Microstructure}

A modified layer close to the surface can be distinguished from the substrate by means of optical and electronic microscopy. This layer looked white after the Vilella reagent attack but the SEM pictures chosen for the nitrided layer analysis and the OM micrograph are not shown in this work. From previous works and from the literature, it is known that this layer corresponds to a nitrogen supersatured solution in the martensitic structure called "expanded martensite" ${ }^{8,10}$. It is also well known, that below this layer, there is a nitrogen diffusion zone with a lower nitrogen concentration which it not observed in the metallographic analysis. However, the existence and extent of this diffusion zone can be inferred from the hardness and nitrogen concentration profiles, because hardness increases with nitrogen concentration. This is due to the lattice expansion and subsequent stresses, which will be shown in the next section.

SEM micrographs were registered to measure this white layer accurately and to observe some features within them with higher magnification. In Fig. 1, the SEM pictures show the nitrided layer with an irregular interphase which not as distinguished as in the $S$ phase in nitrided austenitic stainless steel ${ }^{17}$. The mean thickness of this layer was $10 \mathrm{~mm}$ in all cases except in the $\mathrm{N} 2$ condition, $390{ }^{\circ} \mathrm{C}-5 \mathrm{~h}$, where the layer width was only $8 \mathrm{~mm}$.

The thickness of the nitrided layer was similar for $\mathrm{N} 1, \mathrm{~N} 3$ and N4 samples. On the contrary, the N2 samples which were nitrided at low temperature and short time presented a lower thickness. As in all diffusion process, the combination of time and temperature determined the results. 

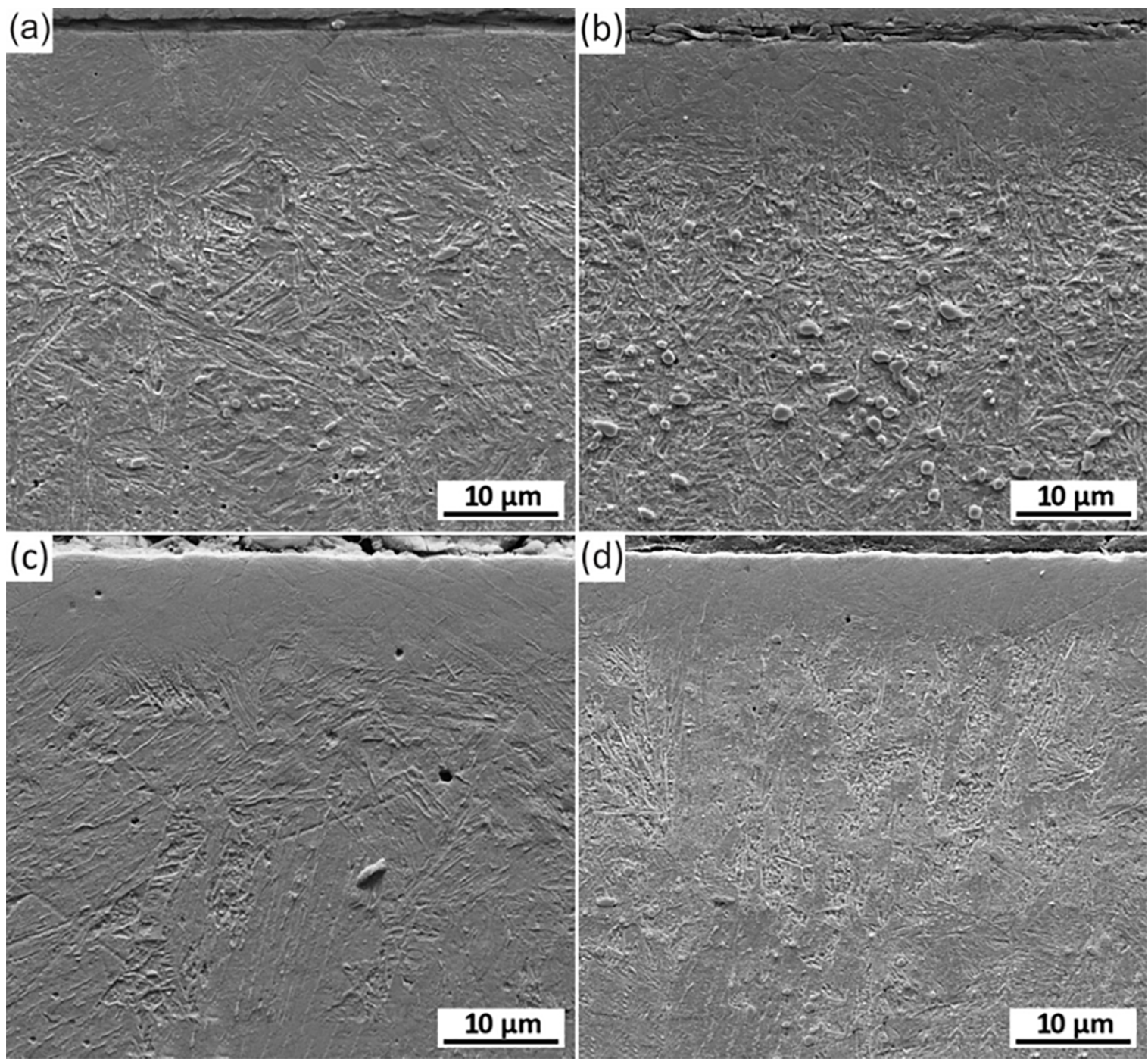

Figure 1. SEM images of nitrided layers for the samples, which were nitrided in different conditions. (a) N1, (b) N3, (c) N2, (d) N4.

It is worth mentioning that with the combination of high temperature and short time, it is possible to get a nitrided layer with similar thickness to that obtained with a traditional N1 treatment.

In a closer analysis, the classical acicular martensitic structure ${ }^{18}$ can be observed in the nitrided layers, especially of N1 and N3 samples (first row). This could be due to a higher nitrogen content in the zone close to the surface, which encourages martensite structure formation, as it was reported in the literature ${ }^{19}$. This structure was also detected in the substrate below the white layer, for all samples.

The nitrided layers structures were analyzed by XRD. In the untreated sample, tempered martensite $(\alpha-\mathrm{Fe})$ and retained austenite $(\gamma)$ peaks were detected. In all nitrided samples, nitrogen "expanded martensite" $\left(\alpha_{N}\right)$ peaks were observed in the diffractograms (Fig. 2).

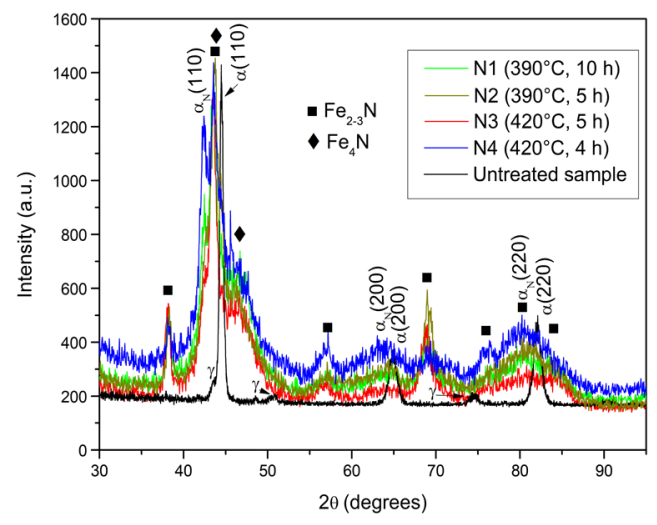

Figure 2. Diffractograms of different nitrided samples. 
This phase corresponds to a nitrogen supersatured solid solution which has been already mentioned in the literature ${ }^{8,10}$. The $\alpha_{\mathrm{N}}$ peaks are broadened and shifted towards lower diffraction angles in relation to the $\alpha$-Fe peaks of the blank (untreated) sample. In the N4 sample, the $\alpha_{\mathrm{N}}$ content was higher because $\alpha_{N}(110)$ peak at $42.6^{\circ}$ was clearly higher. In all nitrided samples, the lattice expansion lattice was similar. Moreover, $\varepsilon-\mathrm{Fe}_{2-3} \mathrm{~N}$ iron nitrides reflections were detected and $\gamma^{\prime}-\mathrm{Fe}_{4} \mathrm{~N}$ in a lower proportion (only two peaks corresponding to these nitrides were clearly detected). Regarding the $\varepsilon-\mathrm{Fe}_{2-3} \mathrm{~N}$ iron nitrides, it can be stated that $\mathrm{Fe}_{3} \mathrm{~N}$ was present in $\mathrm{N} 1, \mathrm{~N} 2$ and $\mathrm{N} 3$ samples. In the $\mathrm{N} 4$ sample, one of the reflections of this phase was not observed but the pattern corresponded to $\mathrm{Fe}_{2} \mathrm{~N}$. The $\alpha_{\mathrm{N}}$ content was higher for the N4 than for the other samples considering the relative intensities of the peaks. The $\mathrm{N} 1$ and N3 samples had less $\alpha_{\mathrm{N}}$ content and in general, the diffractograms were similar. If there was a time-temperature threshold curve (that separate $\mathrm{N}$ in solution $\left(\alpha_{\mathrm{N}}\right)$ from $\mathrm{Fe}$ nitrides) similar to that of the austenitic stainless steel for martensitic stainless steel ${ }^{20}$, the process conditions of $\mathrm{N} 1$ and N3 might be crossing the curve in different places (high temperature-short time (N3) and low temperature- long time (N1)). On the contrary, the N4 sample with less process time would be under the curve. Consequently, in the last case the sample had less iron nitrides. The expanded austenite phase peaks were not detected in any cases in the nitrided samples. This could be due to the background noise and the superposition with other phases in the diffractograms. These results coincide with those from other authors who have reported that the nitrided layer is composed of $\alpha_{\mathrm{N}}$ and $\varepsilon-\mathrm{Fe}_{2-3} \mathrm{~N}$ when the nitriding process is performed at temperatures lower than $450{ }^{\circ} \mathrm{C}^{8,10,14}$. These $\varepsilon-\mathrm{Fe}_{2-3} \mathrm{~N}$ could be $\varepsilon$-carbonitrides $\left(\mathrm{Fe}_{2-3}\right.$ $(\mathrm{C}, \mathrm{N}))$ formed as a consequence of the carbon redistribution, as reported in reference 18 . It is worth noticing that $\mathrm{CrN}$ reflections were absent in all the analyzed nitrided samples, such as the (111) reflection at $37.4^{\circ}$ and the (220) at $63.3^{\circ}$.

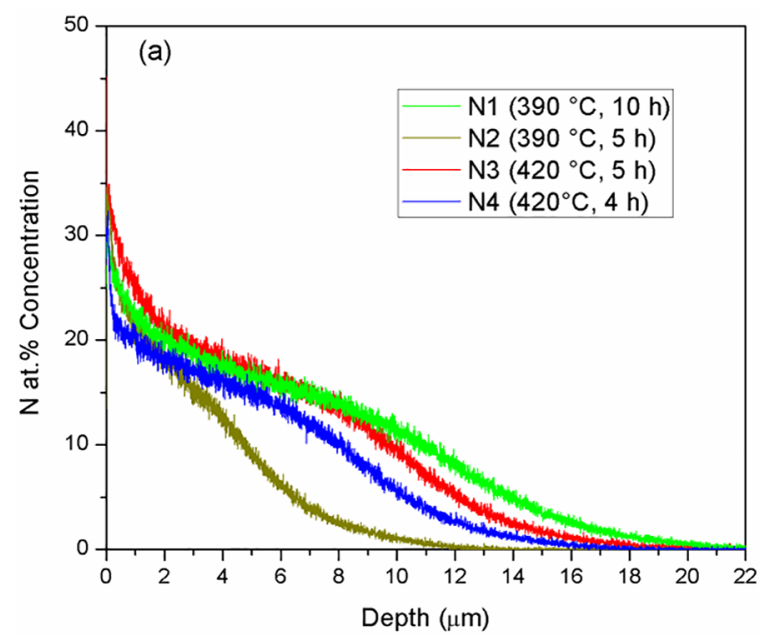

Probably, the time-temperature combination was not enough for the massive precipitation of $\mathrm{CrN}$, as other authors observed in treatments at higher temperatures and longer durations ${ }^{2,12,21}$.

The chemical composition of the nitrided layers was further analyzed by GDOES and their nitrogen profiles are shown in Fig. 3. The nitrogen profiles were similar for N1 and N3 samples and reached a depth of about 18 $\mu \mathrm{m}$; however, in the $\mathrm{N} 3$ sample the nitrogen concentration was higher near the surface. The penetration depth of the nitriding treatment (calculated according to DIN 501903 standard) was the lowest in N2 samples, which is in agreement with the previous SEM and hardness depth profile results. The penetration depth was equivalent between the N1 and N3 samples. This could be due to the fact that the nitrogen diffusion coefficient increases with temperature and so the same penetration can be obtained with less time.

The white layer is not only the nitrided layer since lower concentrations of $\mathrm{N}$ can be found deeper in the surface which form the diffusion zone. The GDOES results correspond to what was observed in the SEM micrograph, that is, three thick layers and a thin white layer in case N3 (Fig. 1). The nitrogen concentration was about $30 \%$ at. near the surface in all cases, as it can be seen in Fig. 3(b). This quantity was enough to form different kinds of nitrides and these were detected in all the XRD diffractograms at least in the depth analyzed by the $X$ rays $(2.5-3 \mu \mathrm{m})$.

Moreover, the presence of $\mathrm{Fe}_{2-3} \mathrm{~N}$ was probably prevalent over $\mathrm{Fe}_{4} \mathrm{~N}$ in a zone close to the surface, taking into account that the $\mathrm{N}$ concentration was higher as mentioned before. According to the results, if the $\mathrm{N}$ concentration near the surface was higher in the N3 sample than in the $\mathrm{N} 1$ sample, the amount of Fe nitrides should also be greater.

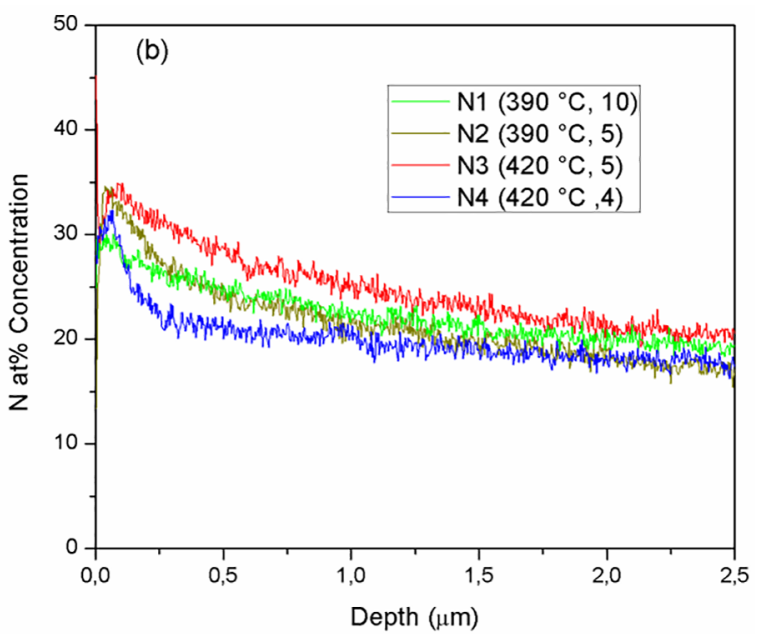

Figure 3. GDOES Nitrogen profiles of nitrided samples (a) until a depth of $22 \mu \mathrm{m}$ (b) closer to the surface, until a depth of $2.5 \mu \mathrm{m}$. 


\subsection{Hardness}

Hardness was measured in two ways: using a Vickers indenter with $25 \mathrm{~g}(245 \mathrm{mN})$ called "microhardness" (Table 2). Besides, the indentation depth was calculated and the values were also shown. In addition, it is usually considered that the total depth affected by the indentation stress field is about 10 times deeper than the actual depth ${ }^{22}$.

The microhardness for the untreated sample was of $(500 \pm 20) \mathrm{HV}$. After the nitriding process, the hardness increased in all samples and it is shown in Table 2. The N2 sample presented the lowest hardness and the total penetration indentation depth exceeded the nitrided layer thickness. Consequently, the hardness measurement was influenced by the substrate and the hardness value did not correspond only to the nitrided layer.

In relation to the hardness profiles, the penetration or nitriding depth was approximately $25 \mu \mathrm{m}$ for both N1 and $\mathrm{N} 3$, as can be seen in Fig. 4. The penetration depth was about $15 \mu \mathrm{m}$ for the N4 sample. In this sample, the profile near the surface is similar to that corresponding to N1 and N3 samples; however, at $15 \mu \mathrm{m}$ depth N4 profile had an abrupt fall until it reached the base material hardness.

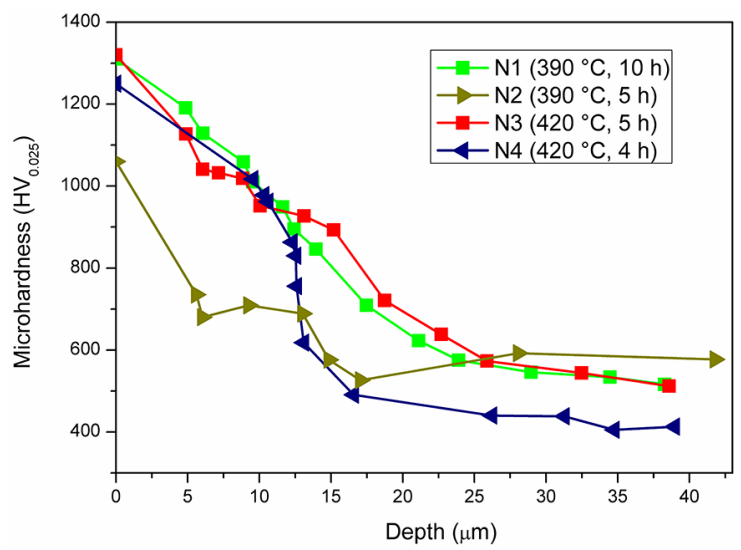

Figure 4. Hardness profiles of nitrided samples.

\subsection{Wear behaviour}

From now onwards, in wear and corrosion experiments the N2 samples (which had the thinnest nitrided layer and the lowest nitrogen in composition profile) were not tested. This is due to the fact there is no sense in making comparison with the other sample groups.

As expected, all nitrided samples had better wear behaviour than the untreated sample (Table 3 ) in the pin on disk tests, because the nitrided layer increases the surface hardness and improves the wear resistance. Moreover, the nitrogen concentration and microstructure have influence on the wear behaviour ${ }^{1}$. The lowest wear volume loss occurred for the N3 sample. The high wear resistance of these samples could be related to the high surface hardness, the hardness depth profile and the phases present in the nitrided layer such as iron nitrides which impart resistance to plastic deformation ${ }^{23}$.

The third column shows the stationary value of the coefficient of friction ( $\mathrm{CoF}$ ) which takes place at the end of the experiment. The friction coefficient was similar before and after the nitriding process for every sample as it can be observed in Table 3. This treatment did not reduce the friction coefficient in these experiments, contrary to what has been reported by other authors in the literature ${ }^{5,23}$.

\subsection{Erosion behaviour}

All nitrided samples presented better wear resistance than the untreated samples (Fig. 5) in the severe erosion wear tests. The mass loss was lower in the N3 sample than in the other samples. The good wear behaviour in this kind of test is related to the microstructure, to the high surface hardness and to the high compressive residual stresses, usually found in the nitrided layer ${ }^{21}$. The better behaviour of N3 can be derived from the fact that the nitrided layer of this sample contained more iron nitrides. These phases confer a better resistance to plastic deformation and they also can stand severe wear, as it was informed in the literature ${ }^{1}$.

Table 2. Microhardness measurements results and calculated mechanical properties

\begin{tabular}{|c|c|c|c|c|}
\hline & N1 & N2 & N3 & N4 \\
\hline Parameters & $390-10$ & $390-5$ & $420-5$ & $420-4$ \\
\hline Microhardness $\left(\mathrm{HV}_{0.025}\right)$ & $1310 \pm 30$ & $1060 \pm 50$ & $1320 \pm 50$ & $1250 \pm 40$ \\
\hline Depth penetration $(\mu \mathrm{m})$ & 0.85 & 0.94 & 0.84 & 0.87 \\
\hline
\end{tabular}

Table 3. Wear results (Pin on disk)

\begin{tabular}{lccc}
\hline \multicolumn{1}{c}{ Samples } & Volume loss $\left(.10^{-3} \mathrm{~mm}^{3}\right)$ & CoF & Depth $(\mu \mathrm{m})$ \\
\hline $\mathrm{N} 1\left(390^{\circ} \mathrm{C}, 10 \mathrm{~h}\right)$ & $6.7 \pm 0.7$ & 0.80 & $1.7 \pm 0.1$ \\
$\mathrm{~N} 3\left(420^{\circ} \mathrm{C}, 5 \mathrm{~h}\right)$ & $4.7 \pm 0.4$ & 0.80 & $1 \pm 0.1$ \\
$\mathrm{~N} 4\left(420^{\circ} \mathrm{C}, 4 \mathrm{~h}\right)$ & $14.4 \pm 1.2$ & 0.87 & $2.2 \pm 0.1$ \\
Untreated & $35 \pm 3.5$ & 0.80 & $3.4 \pm 0.3$ \\
\hline
\end{tabular}




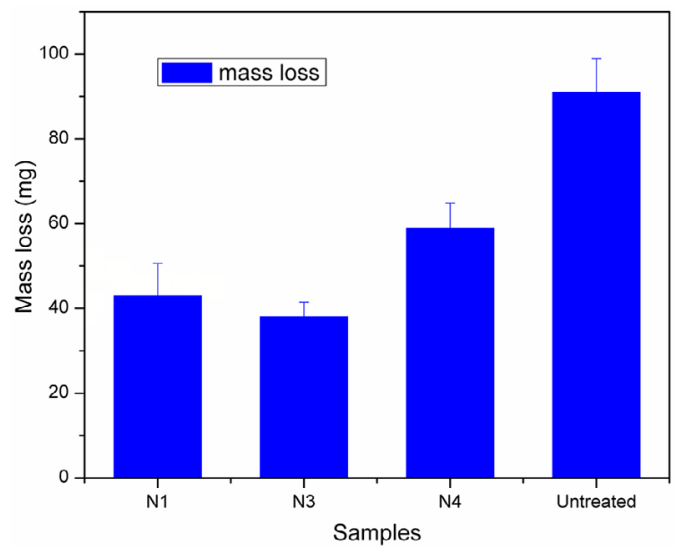

Figure 5. Erosive wear mass loss of different samples.

In addition, the nitrided layer formation introduced high compressive residual stresses, which avoid certain kinds of damage such as ploughing, cutting or microcracks formation caused by the erosive particle impact during the test ${ }^{21,23}$.

\subsection{Corrosion behaviour}

In the polarization test in $\mathrm{NaCl}$ solution, only the $\mathrm{N} 1$ and N3 samples had better corrosion behaviour than the untreated sample (Fig. 6). The corrosion potential value was similar in the untreated sample and in both $\mathrm{N} 1$ and N3, but it was nobler than N4.
However, and what should be highlighted is that the breakdown potential value and the difference between both corrosion and breakdown potential were much higher in N3 than in N1. The N4 sample showed the worst behavior because it did not have any passive region; only active dissolution and current densities $(\mathrm{J})$ were much higher for similar potential values. A quantitative analysis is shown in Table 4.

Regarding corrosion attack morphology, the untreated sample showed severe crevice corrosion signs where the o-ring was placed, as well as pitting corrosion, as it can be observed in Fig. 7(a) and 7(b).

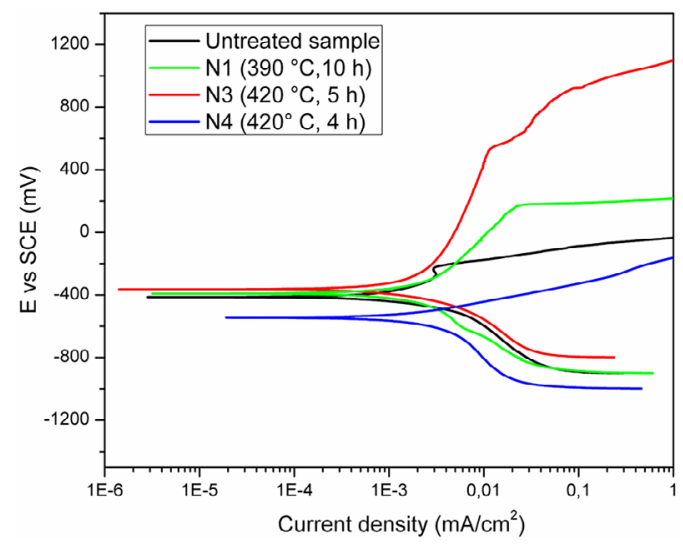

Figure 6. Potentiodynamic curves for nitrided samples.
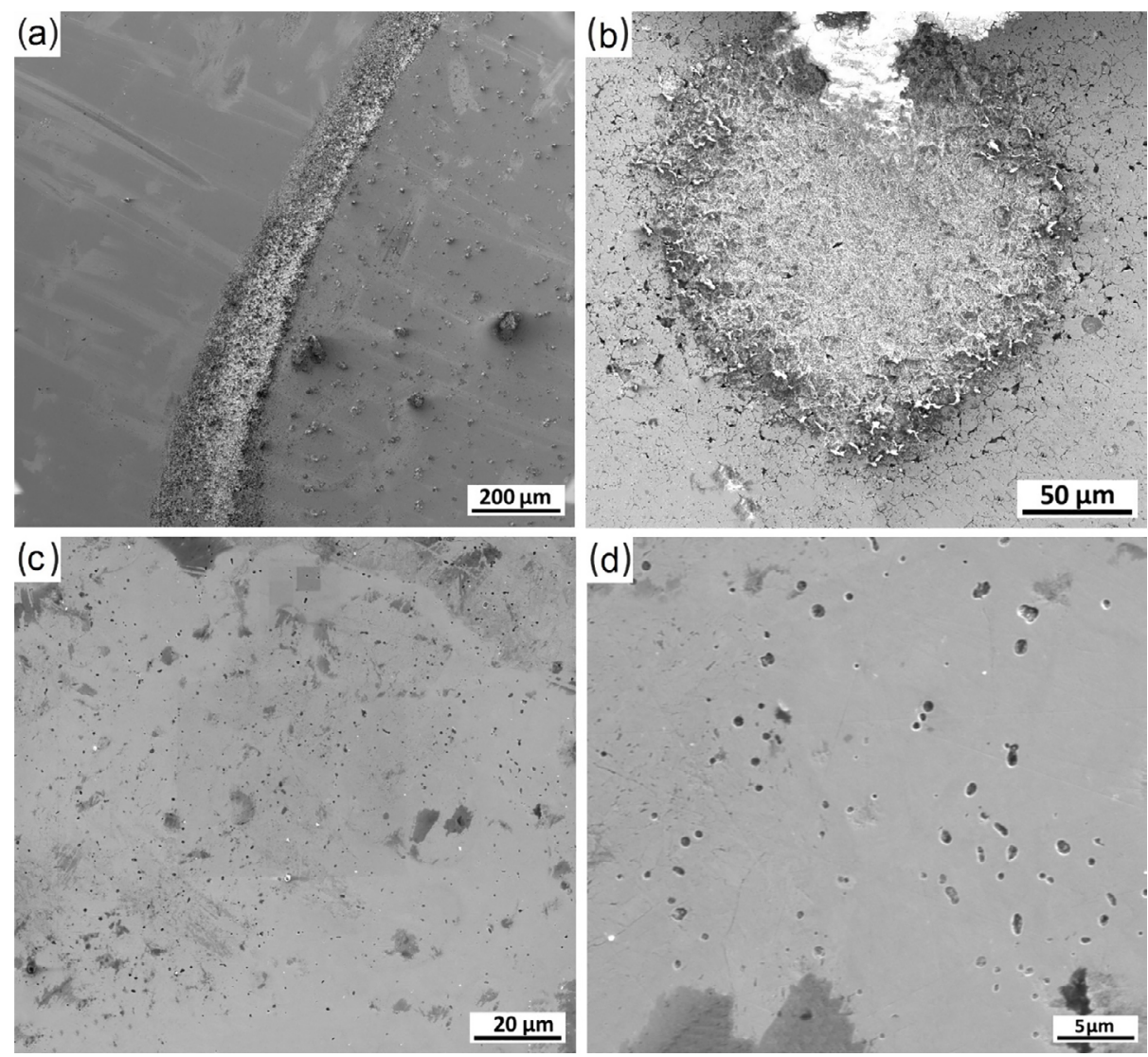

Figure 7. SEM images of corroded zones for different samples (a) and (b) untreated, (c) and (d) N3 sample. 
Table 4. Corrosion results (Anodic polarization)

\begin{tabular}{lcccc}
\hline \multicolumn{1}{c}{ Samples } & $\mathrm{E}_{\text {corr }}(\mathrm{mV})$ & $\mathrm{E}_{\mathrm{BD}}(\mathrm{mV})$ & $\mathrm{E}_{\mathrm{BD}}-\mathrm{E}_{\text {corr }}(\mathrm{mV})$ & $\mathrm{J}-350 \mathrm{mV}\left(\mathrm{mA} / \mathrm{cm}^{2}\right)$ \\
\hline $\mathrm{N} 1\left(390^{\circ} \mathrm{C}, 10 \mathrm{~h}\right)$ & -390 & 170 & 560 & 0.0044 \\
$\mathrm{~N} 3\left(420^{\circ} \mathrm{C}, 5 \mathrm{~h}\right)$ & -365 & 535 & 900 & 0.01 \\
$\mathrm{~N} 4\left(420^{\circ} \mathrm{C}, 4 \mathrm{~h}\right)$ & -545 & - & - & $>>1$ \\
Untreated & -418 & -208 & 210 & 1.00 \\
\hline
\end{tabular}

On the contrary, in the N3 sample, there was a mild attack over the region in contact with the solution (Fig. 7(c)) and some small pits between 1 and $2 \mu \mathrm{m}$ in diameter were detected (Fig. 7(d)).

It was reported that the corrosion behaviour may be related to the iron nitrides, as it has been reported by others authors. A dense nitrided layer which is formed by iron nitrides can act as a barrier to avoid the corrosion substrate ${ }^{12}$, as it occurs for medium alloyed steels.

\section{Conclusions}

The nitriding process on AISI 420 martensitic stainless steel increased its hardness and improved its wear resistance with all the parameters used. In this work, both an increase in the nitriding process temperature and a reduction of the process duration were tried in order to obtain a hard, wear and corrosion resistant layer instead of reducing temperature as it has been reported in the literature. Moreover, this layer consisted of expanded martensite and iron nitrides, but no massive chromium nitrides precipitation was detected by XRD.

Following the results, it can be stated that the combination of time and temperature determines the structure and the properties of the nitrided layer. The increase in temperature increases the nitrogen diffusion coefficient allowing the treatment time to be reduced. A similar layer depth and hardness were obtained for $390{ }^{\circ} \mathrm{C}, 10 \mathrm{~h}$ and $420{ }^{\circ} \mathrm{C}, 5 \mathrm{~h}$ treatments. However, the best wear resistance was achieved for the latter treatment. The other short time conditions, with lower temperature or shorter duration did not yield good results. The bigger difference was observed in the corrosion behaviour where the short treatment $\left(420{ }^{\circ} \mathrm{C}, 5 \mathrm{~h}\right)$ showed the largest passive zone.

Moreover, the use of short nitriding treatments is technologically more convenient due to the fact that it allows energy and money saving.

\section{Acknowledgements}

The authors would like to thank Dr. Eng. M. Agustina Guitar (Saarland University, Germany) for the use of SEM, Dr. Eng. Gregory Marcos and Prof. Thierry Czerwiec (Institut Jean Lamour, France) for GDOES measurements, Vanesa Fuch for XRD, Eng. Bernardo Daga for nanohardness measurements (INTEMA, Argentina).
Moreover, the authors acknowledge the assistance in the experimental part of this work of the students from the Surface Engineering Group of UTN. To the National University of Technology (Faculty of Concepción del Uruguay), Argentina, for the financial support. This work was also carried out in the frame of the SUMA2 Network Project, 7 th Framework Program of the European Commission (IRSES Project No. 318903).

\section{References}

1. Li Y, He Y, Xiu J, Wang W, Zhu Y, Hu B. Wear and corrosion properties of AISI 420 martensitic stainless steel treated by active screen plasma nitriding. Surface and Coatings Technology. 2017;329:184-192

2. Xi YT, Liu DX, Han D. Improvement of corrosion and wear resistances of AISI 420 martensitic stainless steel using plasma nitriding at low temperature. Surface and Coatings Technology. 2008;202(12):2577-2583.

3. Pinedo CE, Monteiro WA. Surface hardening by plasma nitriding on high chromium alloy steel. Journal of Materials Science Letters. 2001;20:147-149.

4. Sousa RRM, Araújo FO, Ribeiro KJB, Dumelow T, Costa JAP, Alves C. Ionic nitriding in cathodic cage of AISI 420 martensitic stainless steel. Surface Engineering. 2008;24(1):52-56.

5. Tuckart W, Forlerer E, Iurman L. Delayed cracking in plasma nitriding of AISI 420 stainless steel. Surface and Coatings Technology. 2007;202:199-202.

6. Tuckart W, Insausti J, Forlerer E, Iurman L. Sliding behaviour of ion nitrided AISI 420 stainless steel. Surface Engineering. 2005;21(5-6):463-468.

7. Corengia P, Walther F, Ybarra G, Sommadossi S, Corbari R, Broitman E. Friction and rolling-sliding wear of DC-pulsed plasma nitrided AISI 410 martensitic stainless steel. Wear. 2006;260:479-485.

8. Alphonsa I, Chainani A, Raole PM, Ganguli B, John PI. A study of martensitic stainless steel AISI 420 modified using plasma nitriding. Surface and Coatings Technology. 2002;150:263-268.

9. Marchev K, Cooper CV, Giessen BC. Observation of a compound layer with very low friction coefficient in ion-nitrided martensitic 410 stainless steel. Surface and Coatings Technology. 1998;99(3):229-233.

10. Kim SK, Yoo JS, Priest JM, Fewell MP. Characteristics of martensitic stainless steel nitrided in a low-pressure RF plasma. Surface and Coatings Technology. 2003;163-164:380-385. 
11. Pinedo CE, Monteiro WA. On the kinetics of plasma nitriding a martensitic stainless steel type AISI 420. Surface and Coatings Technology. 2004;179(2-3):119-123.

12. Li CX, Bell T. Corrosion properties of plasma nitrided AISI 410 martensitic stainless steel in $3.5 \% \mathrm{NaCl}$ and $1 \% \mathrm{HCl}$ aqueous solutions. Corrosion Science. 2006;48(8):2036-2049.

13. Corengia P, Ybarra G, Moina C, Cabo A, Broitman E. Microstructure and corrosion behaviour of DC-pulsed plasma nitrided AISI 410 martensitic stainless steel. Surface and Coatings Technology. 2004;187:63-69.

14. Scheuer CJ, Federal U, Maria DS, Cardoso RP, Brunatto SF. Ultra-low - to high-temperature plasma-assisted nitriding : revisiting and going further on the martensitic stainless steel treatment. Materials Research Express. 2019;6:026529-539.

15. Scheuer CJ, Cardoso RP, Brunatto SF. Low-temperature plasma assisted thermochemical treatments of AISI 420 steel: comparative study of obtained layers. Materials Research. 2015;18(6):1392-1399.

16. Ferreira LM, Brunatto SF, Cardoso RP. Martensitic stainless steels low-temperature nitriding: dependence of substrate composition. Materials Research. 2015;18(3):622-627.
17. Li CX, Bell T. Corrosion properties of active screen plasma nitrided 316 austenitic stainless steel. Corrosion Science. 2004;46:1527-547.

18. Toro A, Sinatora A, Tanaka DK, Tschiptschin AP. Corrosionerosion of nitrogen bearing martensitic stainless steels in seawater-quartz slurry. Wear. 2001;251:1257-64.

19. Mittemeijer EJ, Somers MAJ. Thermochemical surface engineering of steel. Cambridge: Woodhead Publishing; 2014.

20. Bell T, Li CX. Stainless steel: low-temperature nitriding and carburizing. Advanced Materials and Processes. 2002;160(6):49-51.

21. Xi YT, Liu DX, Han D. Improvement of erosion and erosion-corrosion resistance of AISI 420 stainless steel by low temperature plasma nitriding. Applied Surface Science. 2008;254(18):5953-5958.

22. Jedrzejowski P, Klemberg-Sapieha JE, Martinu L. Relationship between the mechanical properties and the microstructure of nanocomposite $\mathrm{TiN} / \mathrm{SiN}_{1.3}$ coatings prepared by low temperature plasma enhanced chemical vapor deposition. Thin Solid Films. 2003;426(1-2):150-159.

23. Xi YT, Liu DX, Han D, Han ZF. Improvement of mechanical properties of martensitic stainless steel by plasma nitriding at low temperature. Acta Metallurgica Sinica (English Letters). 2008;21(1):21-29. 